\title{
Shifts in the Skin-Associated Microbiota of Hatchery-Reared Common Snook Centropomus undecimalis During Acclimation to the Wild
}

\author{
Andrea M. Tarnecki ${ }^{1}$ (D) Nathan P. Brennan ${ }^{1} \cdot$ Ryan W. Schloesser ${ }^{1} \cdot$ Nicole R. Rhody $^{2}$ \\ Received: 14 May 2018 / Accepted: 29 August 2018 / Published online: 6 September 2018 \\ (C) The Author(s) 2018
}

\begin{abstract}
The skin-associated microbiota of fish competes against pathogens for space and nutrients, preventing colonization by harmful bacteria encountered during environmental transitions such as those faced during stock enhancement. Thus, alterations in bacterial community structure during release of cultured fish have important implications for health of these individuals. This study investigated microbiota structure during acclimation of juvenile hatchery-reared common snook Centropomus undecimalis to the wild by comparing skin-associated microflora among snook in captivity, after $48 \mathrm{~h}$ of acclimation at release sites, and from the wild. After two days of acclimation, the microbiota of hatchery-reared snook mirrored that observed on wild snook. Relative abundances of potential pathogens were higher in captive fish, whereas acclimated and wild fish harbored bacterial taxa influenced by geographical factors and water quality at release sites. Predicted microbiota function of acclimated and wild fish showed higher production of protective amino acids and antimicrobials, identifying a mechanism for microbial supplementation of the immune defense of these fish. The two-day transition to wild-type microbiota suggests a temporal scale of hours associated with bacterial succession indicating that the microbiota, whose structure is vital to fish health, aids in acclimation of fish to new environments during stock enhancement efforts.
\end{abstract}

Keywords Common snook $\cdot$ Centropomus undecimalis $\cdot$ Microbiota $\cdot$ Stock enhancement $\cdot$ Immunity

\section{Introduction}

Common snook Centropomus undecimalis, a catadromous estuarine species of the Western Atlantic, is a marine sportfish that contributes to the Florida marine recreational fishery whose sales alone are valued at $\$ 10$ billion each year [1]. However, sensitivity to cold and red tide as well as habitat loss have historically threatened the fishery; thus, the species is a prime candidate for stock enhancement efforts. There is an active stocking program for common snook to test the effectiveness of stock enhancement as a fishery management tool

Electronic supplementary material The online version of this article (https://doi.org/10.1007/s00248-018-1252-7) contains supplementary material, which is available to authorized users.

Andrea M. Tarnecki

atarnecki@mote.org

1 Mote Marine Laboratory, 1600 Ken Thompson Parkway, Sarasota, FL 34236, USA

2 Mote Aquaculture Research Park, 874 WR Mote Way, Sarasota, FL 34240, USA and develop techniques to optimize post-release survival. Brennan et al. [2] demonstrated a $1.78 \times$ increase in survival by allowing juvenile snook to acclimate within predator-free enclosures for three days prior to release into estuarine environments. The authors hypothesized that increased survival was primarily due to learning predator avoidance, but the fish also benefit from learning to feed in the wild and recovering from the handling and stress associated with transport from the hatchery to the release sites.

In addition to behavioral and physiological adaptations during and post-release, the innate immune system of fish must be capable of quickly responding to the bacterial species unique to the new environment. Microbial communities, termed microbiota, associated with fish play a significant role in the health of their host, including increasing nutrient availability, boosting immune function, and protecting against opportunistic pathogens through competitive exclusion and production of antimicrobials [3, 4]. Microbiota structure is intimately tied to health and immune function, as stress and disease correlate with a decrease in bacterial diversity and a concurrent increase in the proportion of opportunistic pathogens $[5,6]$, and exposure to beneficial microorganisms can result in 
increased mucosal (skin, gill, gastrointestinal) immunity [7]. Immunity at mucosal surfaces is of great importance in fish as it provides the first barrier between the host and environmental pathogenic microorganisms.

Rearing fish in captivity or bringing them into a culture environment from the wild drastically alters the fish microbiota. These differences include decreases in bacterial diversity and changes in taxonomical structure [8-11]. Larval colonization by commensal bacteria guides the development of the fish innate immune system [12]; thus, colonization of fishes by a less diverse bacterial assemblage during rearing in culture systems may offer more available niche environments for pathogen establishment, as well as negatively impact the ability of the immune system to resist infection and disease. Characterizing the changes in microbiota structure during acclimation is a vital first step towards understanding disease susceptibility in newly released individuals. Studies comparing microbiota composition and immune status between cultured, acclimated, and wild fish are absent from the literature, and to our knowledge, the ability of the microbiota of captive fish to adapt to the wild environment is unknown.

This study aimed to develop and employ a replicable approach to investigate shifts in microbiota structure and innate immune parameters during wild acclimation of juvenile hatchery-reared common snook in order to increase understanding of the benefit of an acclimation period to postrelease survival.

\section{Methods}

\section{Snook Rearing and Release}

Snook reared in this study came from two separate spawning events. The first spawn originated from captive adult broodstock held and maintained at the Mote Aquaculture Research Park (MAP). Broodfish at MAP were maintained in large $(48,000 \mathrm{~L})$ indoor tanks and induced to spawn as previously described $[13,14]$. The second spawn originated from strip spawning of wild adult common snook from Tampa Bay (Florida, USA) as previously described [15]. Regardless of spawn source (wild vs captive spawned fish), eggs hatched at MAP in three separate $100 \mathrm{~L}$ conical tanks. Newly hatched larvae were subsequently transferred from the egg hatchers and volumetrically stocked $\left(200 \mathrm{~L}^{-1}\right)$ into individual rearing tanks $\left(3.3 \mathrm{~m}^{3}\right)$. The fish were cultured using standard protocols [16] and remained in a recirculating aquaculture system until the time of tagging and release. Fish from the first spawn were released at 186 days post-hatch (dph), and fish from the second spawn were released at $117 \mathrm{dph}$. One month prior to release, all juvenile snook ( $85-158 \mathrm{~mm}$ total length, TL) were fitted with coded wire tags to provide a unique identification of the cohort and release location for each fish as in Brennan et al. [17]. After tagging, snook were graded and allocated in rearing tanks by size, smalls $(56-116 \mathrm{~mm}$ TL) and larges (117-158 mm TL). At the time of release, a live hauler transported fish to two tidal creeks located in Sarasota, Florida, USA: Whitaker bayou (27.357 N, 82.547 W) and Hudson bayou $(27.327 \mathrm{~N}, 82.536 \mathrm{~W})$. A total of 50 randomly selected snook were stocked into a single cage enclosure $\left(1 \mathrm{~m}^{3}\right)$ in each creek. This enclosure allowed them to acclimate to the natural environment for $48 \mathrm{~h}$ [2] prior to sample collection and release into the creeks.

\section{Sample Collection}

Three groups of juvenile snook were sampled during the course of the study. Hatchery-reared fish from two separate spawning events were sampled in the hatchery on the day prior to release and will be referred to herein as captive fish (Capt1 and Capt2). As the sampling procedure has the potential to impact the microbiota structure of these individuals, these fish were then moved to a separate holding tank so as not to include them in acclimation cages and future sampling. Following acclimation, individuals were removed and sampled from cages for each spawn at each location immediately prior to release (acclimated fish from hatch1: Whitaker [Accl1W] and Hudson [Accl1-H]; acclimated fish from hatch2: Whitaker [Accl2-W] and Hudson [Accl2-H]). During and between release events, seine nets were used to catch and sample wild juvenile snook of a similar size as those intended for release from the same locations (WildWhitaker [Wild-W], Wild-Hudson [Wild-H]). Hatcheryreared fish from the first spawn were placed into acclimation cages on August 3, 2016, and fish from the second spawn were placed on October 5, 2016. Wild fish were sampled from July 28 to August 23, 2016. A YSI ProPlus multimeter (YSI, Yellow Springs, OH, USA) recorded water quality at each sampling location (initial hatchery tanks, acclimation sites, and wild fish capture sites). Water parameters measured included the following: salinity (psu), temperature $\left({ }^{\circ} \mathrm{C}\right)$, dissolved oxygen ( $\mathrm{mg} \mathrm{L}^{-1}$ ), $\mathrm{pH}$, and turbidity (FNU).

In order to obtain sufficient volumes of external mucus to perform the desired tests, the mucus from three individual snook was pooled to make one sample. A sterile spatula removed external mucus by gentle scraping, and mucus was held on ice until arrival at the laboratory $(\sim 4 \mathrm{~h})$. Each fish was measured (TL, mm) following mucus sampling. Samples were gently mixed, and a sterile cotton swab was used to sample a portion of the mucus for microbiota analysis. Remaining mucus was centrifuged at $2,630 \mathrm{x}$ g at $4{ }^{\circ} \mathrm{C}$ for $15 \mathrm{~min}$ to remove debris [18] and divided into smaller aliquots for immune parameter measurements. The aliquots and swabs were stored at $-80^{\circ} \mathrm{C}$ until further analysis. 


\section{Sample Processing}

DNA was extracted from swabs using the PowerSoil $®$ DNA Isolation Kit (MO BIO Laboratories, Inc., Carlsbad, CA, USA) following manufacturer's instructions. PCR was performed on the V4 variable region of the 16S rRNA gene using the HotStarTaq Plus Master Mix Kit (Qiagen, Valencia, CA, USA) and the primers $515 \mathrm{~F} / 806 \mathrm{R}$ under the following conditions: $94^{\circ} \mathrm{C}$ for $3 \mathrm{~min}$, followed by 28 cycles at $94^{\circ} \mathrm{C}$ for $30 \mathrm{~s}$, $53^{\circ} \mathrm{C}$ for $40 \mathrm{~s}$, and $72{ }^{\circ} \mathrm{C}$ for $1 \mathrm{~min}$, with a final extension step of $72{ }^{\circ} \mathrm{C}$ for $5 \mathrm{~min}$. PCR products were pooled in equal proportions based on molecular weight and DNA concentration, purified with calibrated Ampure XP beads, and sequenced using the Illumina MiSeq platform (Illumina, Inc., San Diego, CA, USA) following standard protocols. Sequencing was performed at MR DNA (www.mrdnalab.com, Shallowater, TX, USA). Resulting sequences were processed using the MiSeq SOP ([19], accessed 1 Mar 2017) in Mothur v.1.38.1 ([20], accessed 8 December 2017). Operational taxonomic units (OTUs) were defined at $97 \%$ sequence similarity [21] and classified to the lowest taxonomic level using SILVA [22] and a bootstrap cut-off of 50\%. Mothur was used to calculate Good's coverage, diversity indices (bacterial richness as defined by total number of OTUs, and Shannon's Evenness Index (SEI)), and rarefaction curves. The resulting OTU abundance table was loaded into Primer v6 [23] for nonparametric statistics to allow for comparisons between fish groups.

Innate immune parameters analyzed in this study included superoxide dismutase (SOD) and alkaline phosphatase (AKP). Mucus samples were assayed for total protein using the Bradford Protein Assay (Bio-Rad Laboratories, Inc., Hercules, CA, USA) based on the method by Bradford [24]. SOD activity was measured using the Superoxide Dismutase Assay Kit (Cayman Chemical, Ann Arbor, MI, USA) which quantifies the activity of the three types of SOD (cytosolic $\mathrm{Cu} /$ $\mathrm{Zn}$, mitochondrial Mn, and extracellular FeSOD). AKP activity was measured as described by Subramanian et al. [25]. Enzyme activities were adjusted for total protein content.

\section{Data Analysis}

Number of sequences per sample were rarefied to the sample with the least number of sequences $(14,641)$ prior to calculation of diversity indices and rarefaction curves. Diversity indices (richness, evenness), enzyme activities (SOD, AKP), and TL were compared among fish groups (captive, acclimated, wild) using analysis of variance (ANOVA). Microbiota composition was compared among captive, acclimated, and wild juvenile snook using permutational analysis of variance (PERMANOVA) and analysis of similarities (ANOSIM), and visualized using multidimensional scaling (MDS). OTUs responsible for differences between fish groups were determined using LDA effect size (LEfSe) [26]. Correlations between bacterial taxa and innate immune activity were determined using partial least square (PLS) regression and visualized using clustered image maps (CIM) in the mixOmics package [27] within $\mathrm{R}$ [28]. Predictive functions of the microbial communities were determined using predictive functional profiling of microbial communities (PICRUSt) [29]. Briefly, OTUs were classified using Greengenes [30] database files from May 2013 in Mothur, and a biom file was generated. Data was uploaded into Galaxy (huttenhower.sph.harvard. edu/galaxy/, accessed 9 May 2017) where it was normalized by copy number, and the functional metagenome was predicted using KEGG Orthologs and categorized by function at KEGG Pathway Hierarchy Level 3. Accuracy of PICRUSt predictions was evaluated using the nearest sequence taxon index (NSTI) [29]. The resulting file was loaded into statistical analysis of metagenomic profiles (STAMP) software v2.1.3. Non-bacterial functions were removed (i.e., Human Diseases and Organismal Systems). Differences among groups (captive, acclimated, wild) were determined by ANOVA followed by Tukey-Kramer posthoc tests. KEGG pathways were filtered by $p$ value $(p<0$. $05)$ and effect size $\left(\right.$ eta $\left.^{2}>0.70\right)$.

Data Availability The datasets generated during and analyzed during the current study are available in the Sequence Read Archive repository, www.ncbi.nlm.nih.gov/sra/, SRA Study accession: SRP143622.

\section{Results}

\section{Fish Size and Water Quality}

No mortality occurred in the cages within the $48 \mathrm{~h}$ of acclimation. Total lengths of juvenile snook ranged from 62 to $266 \mathrm{~mm}$ with an overall average of $158 \mathrm{~mm}$ (Table 1). Fish from spawn 2 and wild fish from Whitaker bayou were significantly shorter than fish from spawn 1 . Salinity and dissolved oxygen were slightly higher in initial hatchery tanks than corresponding release and wild sampling sites (Table 2). Dissolved oxygen was generally lower at acclimation sites than in hatchery tanks and wild sites. Turbidity varied between sampling sites.

\section{Microbiota Diversity}

Sequencing resulted in 2,649,228 assembled contigs. Further sequence processing included the following: optimization of sequence length (removal of sequences that ended before the position that $90 \%$ of the sequences ended), removal of sequences with ambiguous base calls, removal of chimeras and singletons, and removal of sequences classified into 
Table 1 Total length \pm standard deviation $(\mathrm{mm})$ of fish in this study. Superscripts denote significance as determined using $\operatorname{ANOVA}(\alpha=0.05)$

\begin{tabular}{lll}
\hline Fish group & $\begin{array}{l}\text { Total individuals sampled } \\
\text { (number of replicates) }\end{array}$ & Total length $(\mathrm{mm} \pm \mathrm{SD})$ \\
\hline Capt1 & $30(10)$ & $198 \pm 18.2^{\mathrm{a}}$ \\
Capt2 & $24(8)$ & $124 \pm 19.7^{\mathrm{c}}$ \\
Accl1-H & $30(10)$ & $195 \pm 17.3^{\mathrm{a}}$ \\
Accl2-H & $24(8)$ & $141 \pm 6.26^{\mathrm{bc}}$ \\
Wild-H & $24(8)$ & $164 \pm 33.6^{\mathrm{ab}}$ \\
Accl1-W & $30(10)$ & $200 \pm 17.5^{\mathrm{a}}$ \\
Accl2-W & $24(8)$ & $121 \pm 12.7^{\mathrm{c}}$ \\
Wild-W & $24(8)$ & $123 \pm 55.4^{\mathrm{bc}}$ \\
\hline
\end{tabular}

nonbacterial lineages. Remaining sequences $(1,663,645$ sequences remained following processing) contained 12,806 OTUs at $97 \%$ sequence similarity, ranging from 180 to 2214 OTUs per sample, with an average of 647 . Sequence coverage was $>96 \%$ for all fish groups as indicated by Good's coverage and rarefaction curves (Fig. 1), suggesting that our sequencing efforts detected the majority of fish-associated bacterial community members.

Bacterial richness was significantly higher in wild samples than in captive and acclimated fish (Fig. 2). Wild fish from Hudson bayou harbored higher richness than wild fish from Whitaker bayou. Acclimated fish generally harbored similar diversity to captive fish, with some significant increases, suggesting a trend towards increased diversity during the acclimation period. These results were similar for evenness (SEI), with captive samples having less even bacterial distributions than wild fish. However, evenness indices were all significantly higher in acclimated fish as compared to initial captive fish, indicating better integration with wild fish in this measurement as opposed to species diversity.

\section{Microbiota Structure}

Microbiota structure was significantly different between each of the eight sample groups as determined by PERMANOVA (pairwise $p \leq 0.002$ ) and ANOSIM (global $p=0.001$, global $R=0.888$ ) (Fig. 3). Pairwise tests within ANOSIM indicated variation in community overlap depending on sample group.
For example, Wild-W and Accl2-W had the lowest $R$ value at 0.411 , suggesting the greatest similarity in microbial community structure between acclimated and wild fishes, whereas greater separation occurred between captive fish and postrelease groups ( $R$ values $>0.995)$.

Proteobacteria dominated the microbiota of all fish groups. However, microbiota structure varied at the phylum level with initial captive samples having higher abundances of Firmicutes and lower abundances of Bacteroidetes and Actinobacteria. Acclimation generally resulted in increases in the groups more largely represented in wild fishes paired with decreases in Firmicutes. Wild fish collected from both Whitaker bayou and Hudson bayou showed similar overall phylum-level patterns. Captive fish from the second spawn had higher abundances of Firmicutes coupled with lower abundances of Proteobacteria than captive fish from the first spawn. Acclimated fish from spawn 1 had less representatives from Chloroflexi and Planctomycetes as compared to their captive and wild counterparts.

At the lowest taxonomic classification, differences between fish groups were apparent (Fig. 4) and LEfSe identified 58 differential OTUs within 46 taxa between groups (Table 3). Core members of the microbiota (present in all 70 samples) included OTUs classified within many of the most abundant taxa including Vibrio (1 OTU), Photobacterium (1 OTU), Psychrobacter (1 OTU), Candidatus Thiobios (1 OTU), Ruegeria (1 OTU), Tropicimonas (1 OTU), Planococcaceae (1 OTU), Rhodobacteraceae (2 OTUs), Comamonadaceae (1
Table 2 Water quality parameters measured at each sampling point

\begin{tabular}{llllll}
\hline Sample & Salinity (psu) & Temperature $\left({ }^{\circ} \mathrm{C}\right)$ & Dissolved oxygen $\left(\mathrm{mg} \mathrm{L}^{-1}\right)$ & $\mathrm{pH}$ & Turbidity (FNU) \\
\hline Capt1 & 32.30 & 28.85 & 6.63 & 8.17 & - \\
Capt2 & 34.55 & 27.30 & 6.44 & 8.59 & - \\
Accl1-H & 32.58 & 31.30 & 3.00 & 7.94 & 15.80 \\
Accl2-H & 30.34 & 28.30 & 2.93 & 8.05 & 180.6 \\
Wild-H & 30.60 & 32.05 & 6.01 & 8.05 & 20.55 \\
Accl1-W & 28.18 & 30.95 & 2.91 & 7.78 & 4.700 \\
Accl2-W & 27.88 & 29.30 & 2.78 & 8.06 & 183.0 \\
Wild-W & 28.39 & 33.68 & 7.26 & 7.99 & 30.79 \\
\hline
\end{tabular}




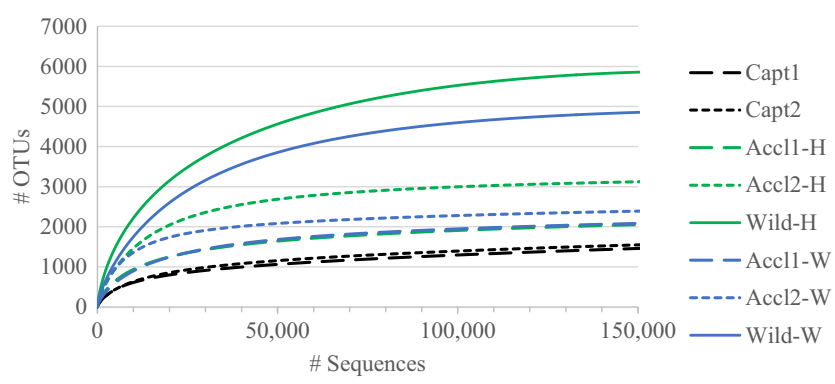

Fig. 1 Rarefaction curves from sequencing of the skin microbiota of common snook juveniles

OTU), Oceanospirillales (1 OTU), and Proteobacteria (1 OTU). These core OTUs made up 5.9-70.5\% of total sequences per sample, with captive fish typically having more (averaging about 55\% total sequences) sequences falling into the core microbiota than wild (averaging 14\% total sequences) and acclimated (averaging $21 \%$ total sequences) fish. On the other hand, all eight fish groups shared 273 OTUs, and sequences attributed to these OTUs made up $72.5 \%$ of total sequences identified in this study. Of these, the most abundant ( $>5 \%$ total sequences standardized to fish group with least number of sequences) include Vibrio, Shewanella, and Planococcaceae. Interesting to note is that only $32.6 \%$ of all sequences could be classified confidently to the genus level using the processing method in this study, including the relatively liberal bootstrap value of $50 \%$.

\section{Predicted Microbiota Function}

NSTI scores averaged $0.11 \pm 0.03$, indicating the ability to use this data to interpret predicated microbial community function (an NSTI score of 0.17 was found to provide accurate metagenome predictions in soil samples) [29]. Twelve KEGG level 3 pathways differed significantly between groups with an effect size of $>0.70$ (Fig. 5). The most significant

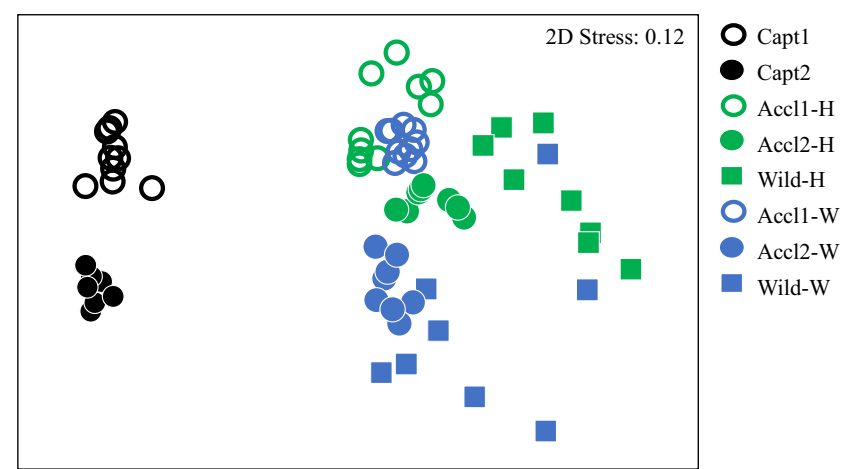

Fig. 3 Multidimensional scaling plot indicating similarity between skin microbiota structures of common snook juveniles

differences included biosynthesis of unsaturated fatty acids $\left(\right.$ eta $\left.^{2}=0.852\right)$ which was highest in captive fish, followed by acclimated and then wild fish, and streptomycin biosynthesis $\left(\right.$ eta $\left.^{2}=0.828\right)$ which showed the exact opposite pattern. Other significant pathways higher in wild and acclimated fish included the following: metabolism of fructose and mannose and C5-branched dibasic acid, biosynthesis of polyketide sugar unit, pantothenate and $\mathrm{CoA}$, valine, leucine and isoleucine, and ansamycins, nucleotide excision repair, and the citrate cycle. Pathways higher in captive fish included the following: phosphonate and phosphinate metabolism and transcription factors.

\section{Innate Immunity}

Captive fish (Capt1, Capt2) demonstrated similar SOD activity as wild fish. SOD activity was significantly higher in acclimated snook in Hudson bayou than wild fish in Hudson bayou (Fig. 2). Although there was a trend for the same pattern in Whitaker, this trend was non-significant. AKP activity was highest in acclimated fish from spawn 1 irrespective of bayou; however, activity was generally lowest in acclimated fish from
Fig. 2 Innate immune parameters and diversity indices of common snook juveniles. Richness was determined by number of OTUs and evenness by Shannon's Evenness Index. Significance as determined by ANOVA is indicated by letters
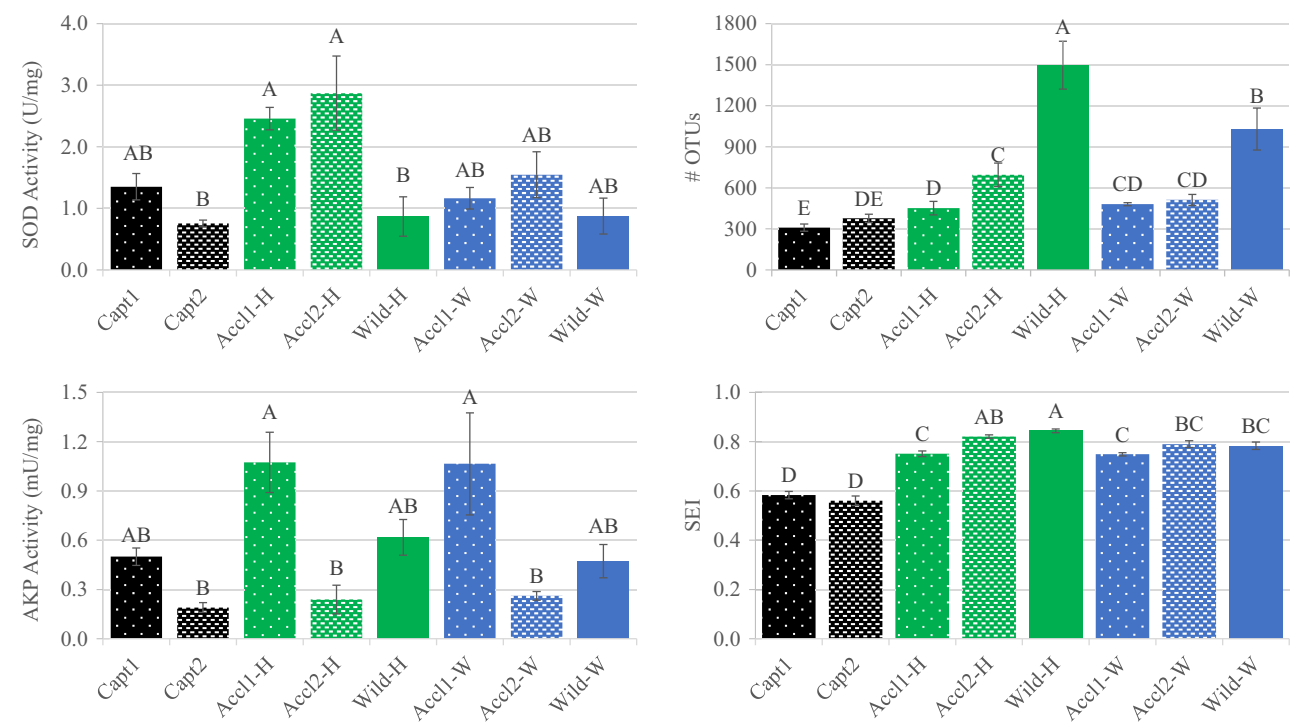
Fig. 4 Relative abundance by percent of lowest possible taxonomic classification identified in sequencing of the skin microbiota of juvenile common snook

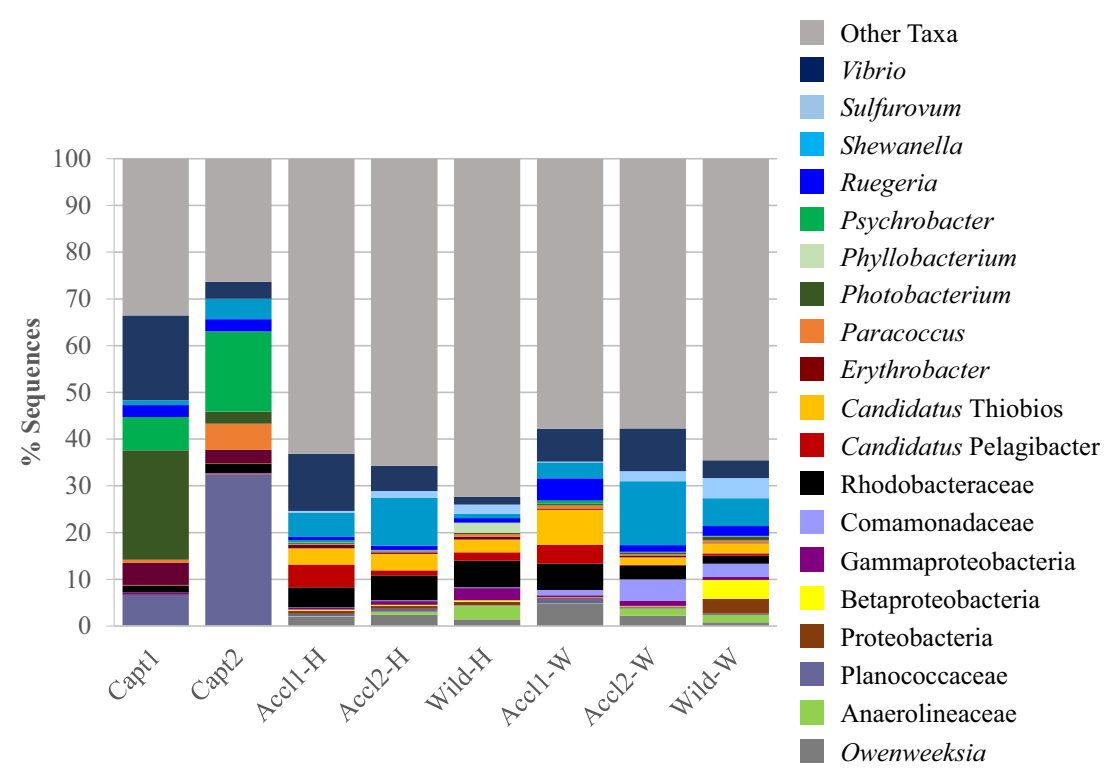

spawn 2. AKP activity correlated positively with TL (Spearman's rank order correlation, coefficient $=0.553$, $p<0.001$ ), whereas SOD activity correlated less but still significantly with TL (coefficient $=0.283, p=0.0179$ ). PLS indicated that the highest correlations between bacterial taxa and fish-associated parameters (TL, AKP, SOD) were positive (> 0.6) between SOD and Armatimonadales, Asticcacaulis and Bradyrhizobium (Alphaproteobacteria), and Xenophilus (Betaproteobacteria). Four taxa identified as sulfurmetabolizing bacteria correlated negatively with TL, and the greatest negative correlation occurred between Sulfurovum, a sulfur-oxidizing bacterium, and TL. Only ML602J-51 (Actinobacteria) and Candidatus Pelagibacter (Alphaproteobacteria) correlated positively with TL at the coefficient examined.

\section{Discussion}

\section{First Description of the Juvenile Snook Microbiota}

This study provides the first description of the juvenile common snook skin microbiota, including the first characterization of the wild snook microbiome. Bacterial species richness detected in snook was generally higher than that of other fish species [31-33]. Fish exhibit high inter-individual variation in their microbiomes [34-37]; thus, pooling individuals likely contributed to higher richness. Despite pooling, inter-sample variation was high, particularly among wild fishes. Our sampling areas were tidal creeks inundated by both fresh and marine waters, with bacterial representatives from both ecosystems interacting with the snook mucosa. These converging environments likely contribute to the high diversity detected in this species.
Geographical location influenced the wild snook microbiota, as skin-associated bacteria differed between fish from Whitaker and Hudson bayous, and acclimated fish acquired bacteria similar to wild fish from their respective release site. However, wild snook shared $85 \%$ of sequences (2253 OTUs) despite sampling location. Interestingly, acclimated fish from spawn 2 demonstrated these geographical differences more so than those from spawn 1 . These results support the hypothesis that microbiome assembly is complex and involves habitat filtering from external environmental parameters and the host (i.e., species-specific differences in mucus composition and immune function) as well as competition with previously established microorganisms [38]. Despite external influences on its structure [31,39], the fish mucosal microbiome is highly divergent from that of the surrounding water [31, 38, 40]. Species-specificity of fish-associated bacterial communities $[3,34,39]$ and influences of genetics on microbiota structure $[33,40]$ demonstrate the importance of host-related factors in determination of fish microbiota assembly.

Juvenile snook shared 12 OTUs across all samples (11 Proteobacteria, 1 Firmicutes). Proteobacteria dominates the core microbiota of fishes [9, 10, 31, 38, 40] suggesting an important relationship between this taxon and its hosts. Juvenile common snook share members of their core microbiota, including Vibrio and Ruegeria, with larval common snook [41], but other members were unique to juveniles, illustrating differences between snook microbiota among developmental stages. Members of the genera Vibrio, Photobacterium, and Psychrobacter are normal inhabitants of marine fish skin [31, 42, 43]. However, core members Candidatus Thiobios and Tropicimonas are unique to snook in this study, providing further evidence towards species-specificity of fish microbiomes. $16 \mathrm{~S}$ rRNA sequences could not identify many shared OTUs to the genus or even family levels; thus, the skin-associated 
Table 3 Number of OTUs in each discriminatory taxon between fish groups as determined by LEfSe

\begin{tabular}{|c|c|c|c|}
\hline OTU ID & Captive & Acclimated & Wild \\
\hline Acholeplasma & 0 & 0 & 1 \\
\hline Acinetobacter & 0 & 1 & 0 \\
\hline Acinetobacter lwoffii & 0 & 1 & 0 \\
\hline Acinetobacter venetianus & 0 & 1 & 0 \\
\hline Alphaproteobacteria & 0 & 1 & 0 \\
\hline Arcobacter & 0 & 1 & 0 \\
\hline Bacillus & 1 & 0 & 0 \\
\hline Bacteroidetes & 0 & 0 & 1 \\
\hline Balneola & 0 & 1 & 0 \\
\hline C111 & 1 & 0 & 0 \\
\hline Candidatus Aquiluna rubra & 1 & 0 & 0 \\
\hline Chryseomicrobium imtechense & 1 & 0 & 0 \\
\hline Comamonadaceae & 0 & 1 & 0 \\
\hline Cryomorphaceae & 0 & 3 & 1 \\
\hline Desulfococcus & 0 & 1 & 1 \\
\hline Desulfosarcina & 0 & 1 & 0 \\
\hline Erythrobacter citreus & 1 & 0 & 0 \\
\hline Flavobacteriaceae & 1 & 2 & 0 \\
\hline GMD14H09 & 0 & 1 & 0 \\
\hline Helicobacteraceae & 0 & 1 & 1 \\
\hline Kytococcus & 0 & 1 & 0 \\
\hline Marinicella & 1 & 0 & 0 \\
\hline Marinococcus & 1 & 0 & 0 \\
\hline Massilia niastensis & 0 & 1 & 0 \\
\hline Microbacteriaceae & 0 & 1 & 0 \\
\hline Microbispora rosea & 0 & 1 & 0 \\
\hline Oleibacter & 1 & 0 & 0 \\
\hline Oleiphilaceae & 0 & 1 & 0 \\
\hline OM60 & 0 & 0 & 1 \\
\hline Paracoccus zeaxanthinifaciens & 0 & 1 & 0 \\
\hline Pelagibacteraceae & 0 & 2 & 0 \\
\hline Persicirhabdus & 0 & 0 & 1 \\
\hline Photobacterium damselae & 1 & 0 & 0 \\
\hline Planococcaceae & 1 & 0 & 0 \\
\hline Psychrobacter celer & 1 & 0 & 0 \\
\hline Psychrobacter pacificensis & 1 & 0 & 0 \\
\hline Rhodobacteraceae & 1 & 1 & 0 \\
\hline Rhodospirillaceae & 0 & 2 & 0 \\
\hline Rhodospirillales & 0 & 2 & 0 \\
\hline Saprospiraceae & 0 & 2 & 0 \\
\hline SHA-20 & 0 & 0 & 1 \\
\hline Spongiibacter tropicus & 0 & 1 & 0 \\
\hline Sulfurovum lithotrophicum & 0 & 0 & 1 \\
\hline Thalassomonas & 0 & 0 & 1 \\
\hline Vesicomyosocius okutanii & 0 & 1 & 0 \\
\hline Vibrio & 1 & 0 & 0 \\
\hline
\end{tabular}

microbiota of common snook represents an underexplored environment for bacterial diversity.

Data from this study indicates that the snook microbiota transitions from a captive structure to wild-type at a temporal scale of hours. As such, sampling these fish after 2 days of acclimation likely missed several transitions in the external bacterial community structure, and better understanding of bacterial succession rates requires hourly assessments of the microbiota.

\section{Captivity Significantly Alters Microbiota Structure}

Captive common snook juveniles harbored decreased bacterial species richness and evenness as compared to acclimated and wild snook. Numerous studies on the gut microbiota of fishes report similar findings [8, 9, 44, 45]. Captive fish rearing in a recirculating aquaculture system maintains a relatively constant salinity, temperature, and oxygen level, generally buffered by the external environment. However, both acclimated and wild fish encountered daily fluxes in salinity, consistently high temperatures, low oxygen levels, and increased turbidity from tidal creeks. The static nature of the culture environment likely plays a large role in the decreased diversity of bacteria associated with the external mucus layer. Conversely, freshwater and marine environments influence the microbiota of fish from tidal creeks, providing bacterial species from both environments with the opportunity to interact and establish on fishes.

Wild and acclimated fish encounter greater diet variability, feeding on living organisms as opposed to the pelleted feed given in captivity, supplying a wider assortment of nutrients that enrich for bacterial communities with diverse metabolic capabilities. The diet of fish also alters the composition of the skin microflora [46]. Indeed, enriched KEGG pathways identified in the microbiota of captive fishes (phosphonate/ phosphinate metabolism and biosynthesis of unsaturated fatty acids) are concomitant with increased consumption of amino acids and glucose $[47,48]$ and indicate a potential interaction between alterations in diet and the structure of the snook skin microbiota. The influence of dietary modifications on the skin-associated bacteria deserves further attention, as Landeira-Dabarca et al. [46] documented a change in 7 days, but it is unknown if these influences are observable within 2 days.

Captive fish harbored greater abundances of bacterial groups known to contain opportunistic fish pathogens, particularly the genera Vibrio and Photobacterium. Vibrio contains 13 species that cause disease in marine fish and diseases resulting from Photobacterium impact multiple species of finfish and sharks [49], and these pathogens are of grave concern in aquaculture. However, $16 \mathrm{~S}$ rRNA sequencing cannot always classify these organisms to the species level [50], and both genera are often reported in association with the external 
Fig. 5 Heatmap of predicted metagenome functions of the skin microbiota of common snook juveniles as determined by PICRUSt analysis

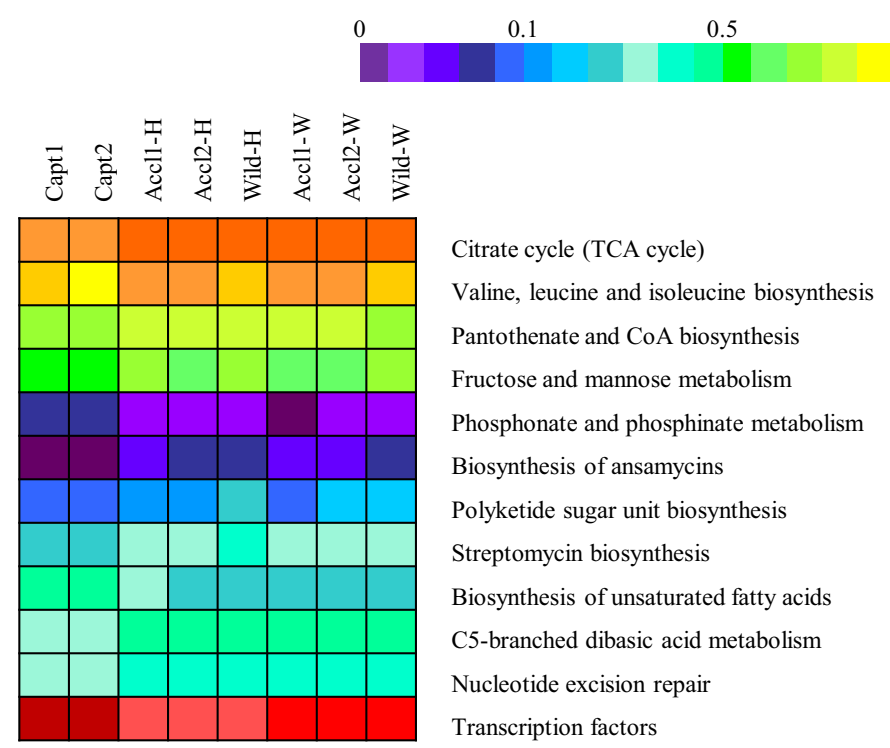

surfaces of fish $[31,42,43]$. The microbiota of captive fishes, including snook in this study and fine flounder Paralichthys adspersus [51], demonstrate reduced valine, leucine, and isoleucine biosynthesis. These amino acids aid in lymphocyte proliferation, and deficiencies increase susceptibility to pathogens [52]. Higher relative abundances of opportunistic taxa and decreased amino acid biosynthesis, alongside a decrease in overall bacterial diversity, warrant further investigation, including identification to the species level and studies that go beyond predictive function, to determine the implications for disease susceptibility in captive fish.

Despite concerns of an altered microbiota (dysbiosis) due to captive rearing, the ability of the bacterial communities to resemble wild-type assemblages within 2 days of acclimation suggests that dysbiosis can be overcome quickly. The newly adapted, diverse microbial community may colonize niches within the mucosal layer to aid in protection against pathogens encountered in the wild as the snook transition between environments.

\section{Innate Immune Activity and the Skin Microbiota Are Impacted by Acclimation}

SOD activity was highest in juvenile snook during acclimation. SOD activity increases in fish exposed to chemical contaminants [53, 54], osmotic shock [55], and hypoxia [56]. The locations in this study were similar in salinity and temperature to those found in the hatchery, but acclimation sites measured the lowest dissolved oxygen levels and the highest SOD activity. Thus, environmental conditions, including oxygen saturation or other unmeasured parameters, influence SOD activity in these fish. On the other hand, patterns in AKP activity in this study correlated well with fish length, indicating that common snook express AKP constitutively and activity increases with fish size.

Bacterial taxa associated with acclimating and/or wild snook express KEGG pathways significant to immunity. Biosynthesis of valine, leucine, and isoleucine, whose protective role against infections was discussed earlier, was highest in acclimated fish, zebrafish experiencing osmotic stress [57] and oil-exposed flounder [58], indicating that environment and contaminants alter the microbial community in a way that increases production of these protective amino acids. Acclimated fish showed increased abundances of Paracoccus zeaxanthinifaciens, a bacterial species that produces the carotenoid zeaxanthin [59]. This pigment is a precursor for vitamin A synthesis and is vital for the health and growth of fishes [60]. Organisms within this genus are common in marine fish species [31, 61, 62] and may represent a natural probiotic. Mannose and fructose metabolism and biosynthesis of ansamycins increased in snook sampled from the bayous. Mannose competes against and prevents attachment of pathogens to the fish epithelium [63], and fructose increases susceptibility of microbes to antibiotics [64]. Ansamycins are antimicrobial compounds that are effective against a variety of fish pathogens, including Mycobacterium, Francisella, and Aeromonas [65], and improve fish survival during infections [66], suggesting that this pathway is activated against environmental microbes in natural ecosystems.

Bacteria play an essential role in nutrient cycling and xenobiotic degradation in aquatic ecosystems, and analysis of microbiota structure and gene expression is useful for environmental monitoring of water quality in natural and aquaculture systems [67, 68]. Patterns in microbiota structure and predicted function reveal that fish associate with bacterial taxa indicative of water quality. Microbiota of acclimated and wild 
juvenile snook contained higher abundances of four sulfurmetabolizing taxa (Desulfococcus, Desulfosarcina [69], Vesicomyoscius okutanii [70], and Sulfurovum lithotrophicum [71]). These bacterial groups are anaerobic, suggesting that the mucosal layer of fish harbors niches free from oxygen that allow for colonization by these microbes. Three genera positively correlated with SOD activity also relate to water quality. Xenophilus contains species that are resistant to toxic chemicals [72, 73], exposure to which results in oxidative stress in fish [53, 54]. High organic nitrogen levels enrich for Armatimonas (of the phylum Armatimonadetes, formerly candidate phylum OP-10) and Bradyrhizobium [74]. Although not specifically measured in this study, the nearest county water quality monitoring stations [75] (Station IDs WH-1 and HUD-3) indicated high total nitrogen levels during our sampling period as compared to historical averages (Online Resource 1). Water quality measurements from other agencies indicate organic enrichment in these bayous [76] (Waterbody IDs FL1936 and FL1953), and our results reflect this data. Acclimated fish harbored higher abundances of Acinetobacter venetianus, a known alkane-degrader [77], and predicted function of wild and acclimated microbiota showed patterns similar to those identified by BrownPeterson et al. [58] within the gill microbiota of southern flounder Paralichthys lethostigma exposed to weathered crude oil-contaminated sediments. These results suggest the potential for fish-associated bacterial taxa to act as biomarkers for water quality in aquatic ecosystems.

\section{Conclusions}

This study provides the first investigation into the adaptation of fish external microbiota to rapid movements between ecosystems such as those experienced in stock enhancement efforts. Results indicate that, within 2 days in predator-free enclosures, bacterial richness and evenness increased from initial captive measurements and microbiota structure changed significantly to reflect communities associated with wild fish, including differences identified between geographic locations. While captive fish harbored higher abundances of potential opportunistic pathogens, adaptation to the wild excluded these microbes from the external microbiota. Bacterial communities associated with fishes provide insight into water quality within the ecosystem, including the presence of organic enrichment and chemical contaminants. Overall, the skin-associated microbiota was able to quickly adapt to the wild environments, suggesting that bacteria, which play a vital role in health and disease resistance in their hosts, aid in acclimation of fishes to a new environment.

Acknowledgements We thank the Mote Fisheries Ecology and Enhancement Program staff, volunteers, and students, for their assistance in snook release experiments and capturing of wild snook. We also thank the Mote Marine and Freshwater Aquaculture Research Program staff for producing and rearing the captive snook for these experiments, the Florida Fish and Wildlife Conservation Commission Stock Enhancement Research Facility for aiding fish transport, and the Mote interns and volunteers for their help with fish release and sampling. We thank Marzie Wafapoor for aiding in immune parameter analysis.

Funding Information This study was funded by the Florida Sea Grant (R/LR-A-54).

\section{Compliance with Ethical Standards}

Ethical Approval All applicable international, national, and/or institutional guidelines for the care and use of animals were followed. All procedures performed in studies involving animals were in accordance with the ethical standards of the institution outlined in Mote Marine Laboratory's Animal Welfare Assurance (A4219-01). All experimental protocols were approved by Mote Marine Laboratory's Animal Care and Use Committee (IACUC Approval No. 17-10-KM1 and 16-05-RS2). Snook releases were conducted under Special Activity License SAL16-0104-SCR.

Conflict of Interest The authors declare that they have no conflict of interest.

Open Access This article is distributed under the terms of the Creative Commons Attribution 4.0 International License (http:// creativecommons.org/licenses/by/4.0/), which permits unrestricted use, distribution, and reproduction in any medium, provided you give appropriate credit to the original author(s) and the source, provide a link to the Creative Commons license, and indicate if changes were made.

\section{References}

1. National Marine Fisheries Service (2017) Fisheries economics of the United States, 2015. NOAA Tech Memo. https://doi.org/10. 1017/CBO9781107415324.004

2. Brennan NP, Darcy MC, Leber KM (2006) Predator-free enclosures improve post-release survival of stocked common snook. J Exp Mar Biol Ecol 335:302-311. https://doi.org/10.1016/j.jembe.2006. 04.001

3. Tarnecki AM, Burgos FA, Ray CL, Arias CR (2017) Fish intestinal microbiome: diversity and symbiosis unraveled by metagenomics. J Appl Microbiol 123:2-17. https://doi.org/10.1111/jam.13415

4. Llewellyn MS, Boutin SS, Hoseinifar SH, Derome N (2014) Teleost microbiomes: the state of the art in their characterization, manipulation and importance in aquaculture and fisheries. Front Microbiol 5:207. https://doi.org/10.3389/fmicb.2014.00207

5. Cipriano R (2011) Far from superficial: microbial diversity associated with the dermal mucus of fish. In: Cipriano R, Schelkunov I (eds) Heal Dis Aquat Org Bilater Perspect. MSU Press, East Lansing, pp 156-167

6. Boutin S, Bernatchez L, Audet C, Derôme N (2013) Network analysis highlights complex interactions between pathogen, host and commensal microbiota. PLoS One 8:e84772. https://doi.org/10. 1371/journal.pone.0084772

7. Lazado CC, Caipang CM a (2014) Mucosal immunity and probiotics in fish. Fish Shellfish Immun 39:78-89. https://doi.org/ 10.1016/j.fsi.2014.04.015 
8. Dhanasiri AKS, Brunvold L, Brinchmann MF, Korsnes K, Bergh $\varnothing$, Kiron V (2011) Changes in the intestinal microbiota of wild Atlantic cod Gadus morhua L. upon captive rearing. Microb Ecol 61:20-30. https://doi.org/10.1007/S00248-01

9. Eichmiller JJ, Hamilton MJ, Staley C, Sadowsky MJ, Sorensen PW (2016) Environment shapes the fecal microbiome of invasive carp species. Microbiome 4:44. https://doi.org/10.1186/s40168-0160190-1

10. Baldo L, Riera JL, Tooming-Klunderud A, Albà MM, Salzburger W (2015) Gut microbiota dynamics during dietary shift in eastern African cichlid fishes. PLoS One 10:e0127462. https://oi.org/10. 1371/journal.pone.0127462

11. Bacanu GM, Oprea L (2013) Differences in the gut microbiota between wild and domestic Acipenser ruthenus evaluated by denaturing gradient gel electrophoresis. Rom Biotechnol Lett 18:80698076

12. Galindo-Villegas J, Garcia-Moreno D, de Oliveira S, Meseguer J, Mulero V (2012) Regulation of immunity and disease resistance by commensal microbes and chromatin modifications during zebrafish development. Proc Natl Acad Sci U S A 109:E2605-E2614. https:// doi.org/10.1073/pnas.1209920109

13. Rhody NR, Neidig CL, Grier H et al (2013) Assessing reproductive condition in captive and wild common snook stocks: a comparison between the wet mount technique and histological preparations. T Am Fish Soc 142:979-988. https://doi.org/10.1080/00028487. 2013.788564

14. Rhody NR, Puchulutegui C, Taggart JB, Main KL, Migaud H (2014) Parental contribution and spawning performance in captive common snook Centropomus undecimalis broodstock. Aquaculture 432:144-153. https://doi.org/10.1016/j.aquaculture. 2014.04.022

15. Yanes-Roca C, Rhody NR, Nystrom M, Wittenrich ML, Main KL (2012) Embryonic and early larval development in hatchery-reared common snook. N Am J Aquac 74:499-511

16. Hauville MRS (2014) Larviculture and nutrition of three of Florida's high value food and stock enhancement finfish, common snook (Centropomus undecimalis), Florida pompano (Trachinotus carolinus) and red drum (Sciaenops ocellatus). Dissertation, University of Stirling, Stirling

17. Brennan NP, Leber KM, Blankenship HL, Ransier JM, DeBruler Jr $\mathrm{R}$ (2005) An evaluation of coded wire and elastomer tag performance in juvenile common snook under field and laboratory conditions. N Am J Fish Manag 25:437-445. https://doi.org/10.1577/ M04-003.1

18. Ross NW, Firth KJ, Wang A, Burka JF, Johnson SC (2000) Changes in hydrolytic enzyme activities of naive Atlantic salmon Salmo salar skin mucus due to infection with the salmon louse Lepeophtheirus salmonis and cortisol implantation. Dis Aquat Organ 41:43-51

19. Kozich JJ, Westcott SL, Baxter NT, Highlander SK, Schloss PD (2013) Development of a Dual-Index Sequencing Strategy and Curation Pipeline for Analyzing Amplicon Sequence Data on the MiSeq Illumina Sequencing Platform. Applied and Environmental Microbiology 79(17):5112-5120

20. Schloss PD, Westcott SL, Ryabin T, Hall JR, Hartmann M, Hollister EB, Lesniewski RA, Oakley BB, Parks DH, Robinson CJ, Sahl JW, Stres B, Thallinger GG, Van Horn DJ, Weber CF (2009) Introducing mothur: open-source, platform-independent, community-supported software for describing and comparing microbial communities. Appl Environ Microbiol 75(23):7537-7541

21. Rosselló-Mora R, Amann R (2001) The species concept for prokaryotes. FEMS Microbiol Rev 25(1):39-67

22. Quast C, Pruesse E, Yilmaz P, Gerken J, Schweer T, Yarza P, Peplies J, Glöckner FO (2012) The SILVA ribosomal RNA gene database project: improved data processing and web-based tools. Nucleic Acids Res 41(D1):D590-D596

23. Clarke K, Gorley R (2006) PRIMER v6: user manual/tutorial. PRIMER-E, Plymouth

24. Bradford MM (1976) A rapid and sensitive method for the quantitation of microgram quantities of protein utilizing the principle of protein-dye binding. Anal Biochem 72(1-2):248-254

25. Subramanian S, MacKinnon SL, Ross NW (2007) A comparative study on innate immune parameters in the epidermal mucus of various fish species. Comp Biochem Physiol Part B Biochem Mol Biol 148(3):256-263

26. Segata N, Izard J, Waldron L, Gevers D, Miropolsky L, Garrett WS, Huttenhower C (2011) Metagenomic biomarker discovery and explanation. Genome Biol 12:R60. https://doi.org/10.1186/gb-201112-6-r60

27. González I, Lê Cao K, Davis MJ, Déjean S (2012) Visualising assocations between paired 'omics' data sets. BioData Mining 5(1):19. https://doi.org/10.1186/1756-0381-5-19

28. R Core Team (2016) R: A language and environment for statistical computing. R Foundation for Statistical Computing, Vienna

29. Langille MG, Zaneveld J, Caporaso JG et al (2013) Predictive functional profiling of microbial communities using 16S rRNA marker gene sequences. Nat Biotechnol 31:814-821

30. DeSantis TZ, Hugenholtz P, Larsen N, Rojas M, Brodie EL, Keller K, Huber T, Dalevi D, Hu P, Andersen GL (2006) Greengenes, a chimera-checked 16S rRNA gene database and workbench compatible with ARB. Appl Environ Microbiol 72(7):5069-5072

31. Larsen AM, Bullard SA, Womble M, Arias CR (2015) Community structure of skin microbiome of Gulf killifish, Fundulus grandis, is driven by seasonality and not exposure to oiled sediments in a Louisiana salt marsh. Microb Ecol 70:534-544. https://doi.org/10. 1007/s00248-015-0578-7

32. Ray CL (2016) Characterization of the gut and skin microbiomes of wild-caught fishes from Lake Guntersville, Alabama. Thesis, Auburn University

33. Boutin S, Sauvage C, Bernatchez L, Audet C, Derome N (2014) Inter individual variations of the fish skin microbiota: host genetics basis of mutualism? PLoS One 9:1-17. https://doi.org/10.1371/ journal.pone. 0102649

34. Chiarello M, Villéger S, Bouvier C, Bettarel Y, Bouvier T (2015) High diversity of skin-associated bacterial communities of marine fishes is promoted by their high variability among body parts, individuals and species. FEMS Microbiol Ecol 91:fiv061. https://doi. org/10.1093/femsec/fiv061

35. Lokesh J, Kiron V (2016) Transition from freshwater to seawater reshapes the skin-associated microbiota of Atlantic salmon. Sci Rep 6:19707. https://doi.org/10.1038/srep19707

36. Llewellyn MS, Leadbeater S, Garcia C, Sylvain FE, Custodio M, Ang KP, Powell F, Carvalho GR, Creer S, Elliot J, Derome N (2017) Parasitism perturbs the mucosal microbiome of Atlantic salmon. Sci Rep 7:43465. https://doi.org/10.1038/srep43465

37. Larsen AM, Mohammed HH, Arias CR (2015) Comparison of DNA extraction protocols for the analysis of gut microbiota in fishes. FEMS Microbiol Lett 362:fnu031. https://doi.org/10.1093/ femsle/fnu031

38. Schmidt VT, Smith KF, Melvin DW, Amaral-Zettler LA (2015) Community assembly of a euryhaline fish microbiome during salinity acclimation. Mol Ecol 24:2537-2550. https://doi.org/10. $1111 /$ mec. 13177

39. Larsen A, Tao Z, Bullard SA, Arias CR (2013) Diversity of the skin microbiota of fishes: evidence for host species specificity. FEMS Microbiol Ecol 85:483-494. https://doi.org/10.1111/1574-6941. 12136 
40. Uren Webster TM, Consuegra S, Hitchings M, Garcia de Leaniz C (2018) Inter-population variation in the Atlantic salmon microbiome reflects environmental and genetic diversity. Appl Environ Microbiol. https://doi.org/10.1128/AEM.00691-18

41. Tarnecki AM, Rhody NR (2017) Microbiota of common snook Centropomus undecimalis larvae exhibiting high mortality. Aquac Res 48:5693-5698

42. Arias CR, Koenders K, Larsen AM (2013) Predominant bacteria associated with red snapper from the northern Gulf of Mexico. J Aquat Anim Health 25:281-289. https://doi.org/10.1080/ 08997659.2013.847872

43. Tarnecki AM, Patterson WF, Arias CR (2016) Microbiota of wildcaught red snapper Lutjanus campechanus. BMC Microbiol 16: 245. https://doi.org/10.1186/s12866-016-0864-7

44. Hennersdorf P, Mrotzek G, Abdul-Aziz MA, Saluz HP (2016) Metagenomic analysis between free-living and cultured Epinephelus fuscoguttatus under different environmental conditions in Indonesian waters. Mar Pollut Bull 110:726-734. https:// doi.org/10.1016/j.marpolbul.2016.05.009

45. Dehler CE, Secombes CJ, Martin SAM (2017) Environmental and physiological factors shape the gut microbiota of Atlantic salmon parr (Salmo salar L.). Aquaculture 467:149-157. https://doi.org/10. 1016/j.aquaculture.2016.07.017

46. Landeira-Dabarca A, Sieiro C, Alvarez M (2013) Change in food ingestion induces rapid shifts in the diversity of microbiota associated with cutaneous mucus of Atlantic salmon Salmo salar. J Fish Biol 82:893-906

47. Bortoluzzi C, Pedroso AA, Mallo JJ, Puyalto M, Kim WK, Applegate TJ (2017) Sodium butyrate improved performance while modulating the cecal microbiota and regulating the expression of intestinal immune-related genes of broiler chickens. Poult Sci 96: 3981-3993. https://doi.org/10.3382/ps/pex218

48. Zeng Z, Du C, Liu S et al (2017) Glucose enhances tilapia against Edwardsiella tarda infection through metabolome reprogramming. Fish Shellfish Immun 61:34-43. https://doi.org/10.1016/j.fsi.2016. 12.010

49. Austin B (2005) Bacterial pathogens of marine fish. In: Belkin S, Colwell RR (ed) Oceans and Health: Pathogens in the Marine Environment. Springer, Amsterdam, pp 391-413

50. Thompson FL, Iida T, Swings J (2004) Biodiversity of vibrios. Microbiol Mol Biol Rev 68:403-431. https://doi.org/10.1128/ MMBR.68.3.403

51. Ramírez C, Romero J (2017) Fine flounder (Paralichthys adspersus) microbiome showed important differences between wild and reared specimens. Front Microbiol 8:1-12. https://doi. org/10.3389/fmicb.2017.00271

52. Li P, Yin Y-L, Li D, Woo Kim S, Wu G (2007) Amino acids and immune function. Br J Nutr 98:237. https://doi.org/10.1017/ S000711450769936X

53. Zhang W, Liu W, Zhang J, Zhao H, Zhang Y, Quan X, Jin Y (2012) Characterisation of acute toxicity, genotoxicity and oxidative stress posed by textile effluent on zebrafish. J Environ Sci 24:2019-2027

54. Bhattacharya A, Bhattacharya S (2007) Induction of oxidative stress by arsenic in Clarias batrachus: involvement of peroxisomes. Ecotoxicol Environ Saf 66:178-187

55. Martínez-Alvarez RM, Hidalgo MC, Domezain A, Morales AE, García-Gallego M, Sanz A (2002) Physiological changes of sturgeon Acipenser naccarii caused by increasing environmental salinity. J Exp Biol 205:3699-3706

56. Marcon JL, Wilhelm Filho D (1999) Antioxidant processes of the wild tambaqui, Colossoma macropomum (Osteichthyes, Serrasalmidae) from the Amazon. Comp Biochem Physiol C Pharmacol Toxicol Endocrinol 123:257-263. https://doi.org/10. 1016/S0742-8413(99)00030-4
57. Davis DJ (2016) Microbiota modulation of behavior and stress responses: implications for neuro-immune research in zebrafish. Dissertation, University of Missouri, Columbia

58. Brown-Peterson NJ, Krasnec M, Takeshita R, Ryan CN, Griffitt KJ, Lay C, Mayer GD, Bayha KM, Hawkins WE, Lipton I, Morris J, Griffitt RJ (2015) A multiple endpoint analysis of the effects of chronic exposure to sediment contaminated with deepwater horizon oil on juvenile southern flounder and their associated microbiomes. Aquat Toxicol 165:197-209

59. Raguenes G, Moppert X, Richert L et al (2004) A novel exopolymer-producing bacterium, Paracoccus zeaxanthinifaciens subsp. payriae, isolated from a "Kopara" mat located in Rangiroa, and atoll of French Polynesia. Curr Microbiol 49:145-151. https:// doi.org/10.1007/s00284-004-4303-x

60. Torrissen OJ, Christiansen R (1995) Requirements for carotenoids in fish diets. J Appl Ichthyol 11:225-230. https://doi.org/10.1111/j. 1439-0426.1995.tb00022.x

61. Zarkasi KZ, Abell GCJ, Taylor RS, Neuman C, Hatje E, Tamplin ML, Katouli M, Bowman JP (2014) Pyrosequencing-based characterization of gastrointestinal bacteria of Atlantic salmon (Salmo salar L.) within a commercial mariculture system. J Appl Microbiol 117:18-27. https://doi.org/10.1111/jam.12514

62. Makridis P, Martins S, Reis J, Dinis MT (2008) Use of probiotic bacteria in the rearing of Senegalese sole (Solea senegalensis) larvae. Aquac Res 39:627-634. https://doi.org/10.1111/j.1365-2109. 2008.01933.x

63. Spring P, Wenk C, Connolly A, Kiers A (2015) A review of 733 published trials on Bio-Mos®, a mannan oligosaccharide, and Actigen $®$, a second generation mannose rich fraction, on farm and companion animals. J Appl Anim Nutr 3:e8. https://doi.org/ 10.1017/jan.2015.6

64. Su YB, Peng B, Han Y et al (2015) Fructose restores susceptibility of multidrug-resistant Edwardsiella tarda to kanamycin. J Proteome Res 14:1612-1620. https://doi.org/10.1021/pr501285f

65. Austin B, Austin D (2012) Bacterial fish pathogens: diseases of farmed and wild fish5th edn. Springer-Praxis, Ltd, United Kingdom

66. Kawakami K, Kusuda R (1990) Efficacy of rifampin, streptomycin and erythromycin against experimental Mycobacterium infection in cultured yellowtail. Bull Japanese Soc Sci Fish 56:51-53. https:// doi.org/10.2331/suisan.56.51

67. Caruso G, La Ferla R, Azzaro M et al (2016) Microbial assemblages for environmental quality assessment: knowledge, gaps and usefulness in the European marine strategy framework directive. Crit Rev Microbiol 42:883-904. https://doi.org/10.3109/ 1040841X.2015.1087380

68. Bentzon-Tilia M, Sonnenschein EC, Gram L (2016) Monitoring and managing microbes in aquaculture - towards a sustainable industry. Microb Biotechnol 9:576-584. https://doi.org/10.1111/ 1751-7915.12392

69. Kleindienst S, Herbst FA, Stagars M, von Netzer F, von Bergen M, Seifert J, Peplies J, Amann R, Musat F, Lueders T, Knittel K (2014) Diverse sulfate-reducing bacteria of the Desulfosarcina/ Desulfococcus clade are the key alkane degraders at marine seeps. ISME J 8:2029-2044. https://doi.org/10.1038/ismej.2014.51

70. DeWall MT, Cheng DW (2011) The minimal genome-a metabolic and environmental comparison. Brief Funct Genomics 10:312-315. https://doi.org/10.1093/bfgp/elr030

71. Inagaki F, Takai K, Nealson KH, Horikoshi K (2004) Sulfurovum lithotrophicum gen. nov., sp. nov., a novel sulfur-oxidizing chemolithoautotroph within the E-proteobacteria isolated from Okinawa trough hydrothermal sediments. Int J Syst Evol Microbiol 54:1477-1482. https://doi.org/10.1099/ijs.0.03042-0

72. Li QF, Sun LN, Kwon SW, Chen Q, He J, Li SP, Zhang J (2014) Xenophilus arseniciresistens sp. nov., an arsenite-resistant 
bacterium isolated from soil. Int J Syst Evol Microbiol 64:19261931. https://doi.org/10.1099/ijs.0.061515-0

73. Blumel S, Busse H-J, Stolz A, Kampfer P (2001) Xenophilus azovorans gen. nov., a soil bacterium that is able to degrade azo dyes of the Orange II type. Int J Syst Evol Microbiol 51:1831-1837

74. Narendrula R (2017) Biochemical and molecular characterization of microbial communities from a metal contaminated and reclaimed region. Dissertation, Laurentian University, Sudbury
75. USF Water Institute (2018) Sarasota County Water Atlas. http:// www.sarasota.wateratlas.usf.edu. Accessed 3 Jan 2018

76. EPA (2012) Waterbody Quality Assessment Report. https:// ofmpub.epa.gov. Accessed 12 Apr 2018

77. Di Cello F, Pepi M, Baldi F, Fani R (1997) Molecular characterization of an n-alkane-degrading bacterial community and identification of a new species, Acinetobacter venetianus. Res Microbiol 148: 237-249. https://doi.org/10.1016/S0923-2508(97)85244-8 